\title{
Functional outcome of anterior cruciate ligament reconstruction using bone-patellar tendon-bone graft: a descriptive observational study from Telangana
}

\author{
K. Jaya Krishna Singh¹, V. K. V. Prasad ${ }^{1}$, T. Ashita Singh²*, Anant A. Takalkar ${ }^{3}$
}

\author{
${ }^{1}$ Department of Orthopaedics, ${ }^{2}$ Department of Microbiology, Mediciti Institute of Medical Sciences, Hyderabad, \\ Telangana, India \\ ${ }^{3}$ Department of Community Medicine, MIMSR Medical College and YCRH, Latur, Maharashtra, India
}

Received: 01 April 2021

Revised: 12 April 2021

Accepted: 13 April 2021

\author{
*Correspondence: \\ Dr. T. Ashita Singh, \\ E-mail: dr.ashitasingh@gmail.com
}

Copyright: () the author(s), publisher and licensee Medip Academy. This is an open-access article distributed under the terms of the Creative Commons Attribution Non-Commercial License, which permits unrestricted non-commercial use, distribution, and reproduction in any medium, provided the original work is properly cited.

\begin{abstract}
Background: The knee joint is the most commonly injured of all joints and the anterior cruciate ligament is the most commonly injured ligament. The bone-patellar tendon-bone (BPTB) autograft is the most commonly used autograft for reconstruction. The bone-patellar tendon-bone autograft has been widely accepted as the gold standard for ACL reconstruction with a high success rate. Objectives of the study were to study the functional outcome of ACL reconstruction using BPTB graft.

Methods: The present descriptive observational study was carried out at department of orthopedics, Mediciti institute of medical sciences, Hyderabad involving 30 patients of ACL tear by simple random sampling method. Patients were then evaluated by both subjectively and objectively. They were evaluated by using Lysholm and Gilquist knee scoring scale. Data was analyzed by using SPSS 24.0 version IBM USA.

Results: Majority of the patients i.e., 13 (43.3\%) were from 26-35 years age group with right sided involvement in $60 \%$. The result was found to be good in 16 i.e., $53.3 \%$, excellent in 10 i.e., $33.3 \%$ and fair in 4 i.e., $13.3 \%$ patients. Prevalence of complications was reported as $23.3 \%$ in our study.

Conclusions: Our study of ACL repair using BPTP gives good to excellent results within a span of one year.
\end{abstract}

Keywords: Functional outcome, ACL reconstruction, BPTB graft

\section{INTRODUCTION}

The knee joint is the most commonly injured of all joints and the anterior cruciate ligament is the most commonly injured ligament. ${ }^{1,2}$ The modern high-speed vehicular trauma and sporting life style has led to increased ligament injuries of the knee. The anterior cruciate ligament forms the pivot in the functional congruence and stability of the knee in association with the other ligaments, capsule, muscles and bone. ${ }^{3,4}$

Anterior knee instability associated with rupture of ACL is a disabling clinical problem in general and especially in athletic individuals. ACL has a poor capacity of healing. The need for surgical correction of ACL injuries arises because, untreated complete injury to the ligament leads to progressive symptomatic instability leading to recurrent injury and damage to the menisci and articular cartilage thus resulting in early osteoarthritis. ${ }^{5-7}$

Numerous authors have described successful reconstruction of ACL (ACLR) with use of autografts (e.g., Patellar tendon, hamstring tendons, distally based iliotibial band (ITB), fascia late etc.) and allografts (e.g., Achillis tendon, tibialis anterior, patellar tendon, hamstring tendons etc.). ${ }^{8-12}$ 
The BPTB autograft is the most commonly used autograft for reconstruction. ${ }^{13-17}$ The bone-patellar tendon-bone autograft has been widely accepted as the gold standard for ACL reconstruction with a high success rate. ${ }^{18-20}$

So, the present study was planned with the objective to analyze the outcome of surgical management of ACL reconstruction using autologous ipsilateral BPTB graft.

Objectives of the study were to study the functional outcome of ACL reconstruction using BPTB graft.

\section{METHODS}

The present descriptive observational study was carried out at department of orthopedics, mediciti institute of medical sciences, Hyderabad. All patients with diagnosis of ACL tear were included during the period of January 2019 to December 2019.

We planned to include all the subjects with ACL tear fulfilling the eligibility criteria of the study approaching to our centre during the period of January 2019 to December 2019 and hence all 30 patients were selected for study.

\section{Inclusion criteria}

Inclusion criteria for the study- anterior cruciate ligament tear confirmed by Latchman test, anterior drawer test, classic pivot shift maneuver of MacIntosh and Galway, flexion-rotation drawer test, Mcmurrays test, valgus and varus test and MRI, patients having age between 15-50 years and those willing to participate after informed consent were included.

\section{Exclusion criteria}

Exclusion criteria for the study excluded patients having below 15 and above 50 years age, pregnant and lactating mothers, ACL injury associated with bone injury around knee, osteoarthritic changes on X-ray and those who are not willing to participate.

Patients with ACL tear meeting inclusion and exclusion criteria were enrolled in our study after consent. Detailed history and thorough clinical examination were carried out with special emphasis on features of ACL injury. Systemic examination and routine blood investigations were carried out. X-ray and MRI of knee was done as indicated. A detailed physical examination of ACL tear under anesthesia was carried out. The data was collected in patient information sheet. Patients were then evaluated by both subjectively and objectively. They were evaluated by using international knee documentation score 2000 (IKDC) and Lysholm and Gilquist knee scoring scale.

\section{Lisholm and Gilquist knee pain scoring system ${ }^{21}$}

It included scoring system like-Excellent-95-100, good84-94, fair-65-83 and poor-64 and less.

\section{Statistical analysis and methods}

Data was collected by using a structured proforma. Data thus was entered in MS excel sheet and analyzed by using SPSS 24.0 version IBM USA. Qualitative data was expressed in terms of percentages and proportions. Quantitative data was expressed in terms of Mean and Standard deviation.

\section{RESULTS}

We included total 30 patients in our study according to eligibility criteria. In our study, majority of the patients i.e., $13(43.3 \%)$ were from $26-35$ years age group followed by 10 i.e., $33.3 \%$ from $15-25$ years, 5 (16.7\%) from 36-45 years group. Least were from $45-55$ years age group i.e., 2 (6.7\%) (Table 1).

Table 1: Distribution according to age.

\begin{tabular}{|llll|}
\hline \multicolumn{1}{|c}{ Variables } & & Frequency & Percentage $(\%)$ \\
\hline \multirow{2}{*}{$\begin{array}{l}\text { Age } \\
\text { group } \\
\text { (years) }\end{array}$} & $15-25$ & 10 & 33.3 \\
\cline { 2 - 4 } & $26-35$ & 13 & 43.3 \\
\hline & $36-45$ & 5 & 16.7 \\
\cline { 2 - 4 } & Total & 2 & 6.7 \\
\hline
\end{tabular}

Male predominance was found in our study. 24 (80\%) patients were males and $6(20 \%)$ patients were females. Male to female ratio was $4: 1$. This was probably because males are more frequently involved in sports and road traffic accidents (Figure 1).

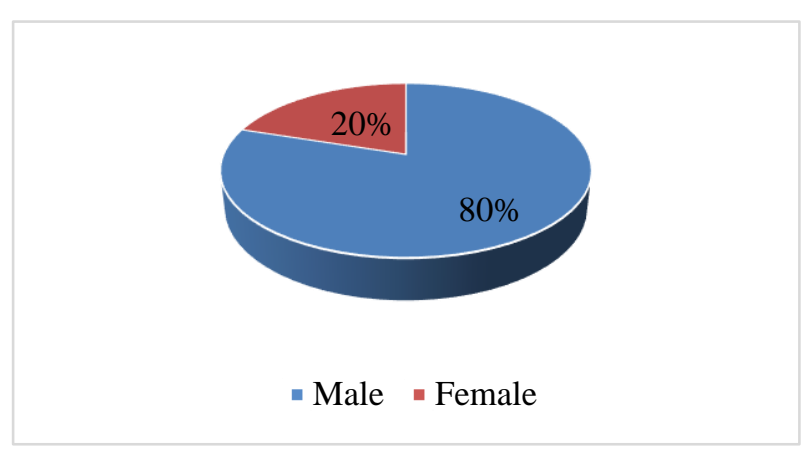

Figure 1: Pie diagram of distribution according to gender.

Out of 30 knee injuries, right sided involvement was seen in 18 patients i.e., $60 \%$ and left sided knee involvement was seen in 12 i.e., $40 \%$ (Table 2).

Table 2: Distribution according to knee involved.

\begin{tabular}{|llll|}
\hline Variables & & Frequency & $\begin{array}{l}\text { Percentage } \\
(\%)\end{array}$ \\
\hline \multirow{3}{*}{ Knee involved } & Right & 17 & 56.7 \\
\cline { 2 - 4 } & Left & 13 & 43.3 \\
\cline { 2 - 4 } & Total & 30 & 100.0 \\
\hline
\end{tabular}


In majority of the patients i.e., $15(50 \%)$, sports were the commonest mode of injury, followed by road traffic accidents in 12 i.e., $40 \%$ and falls in 3 i.e., $10 \%$ patients (Figure 2).

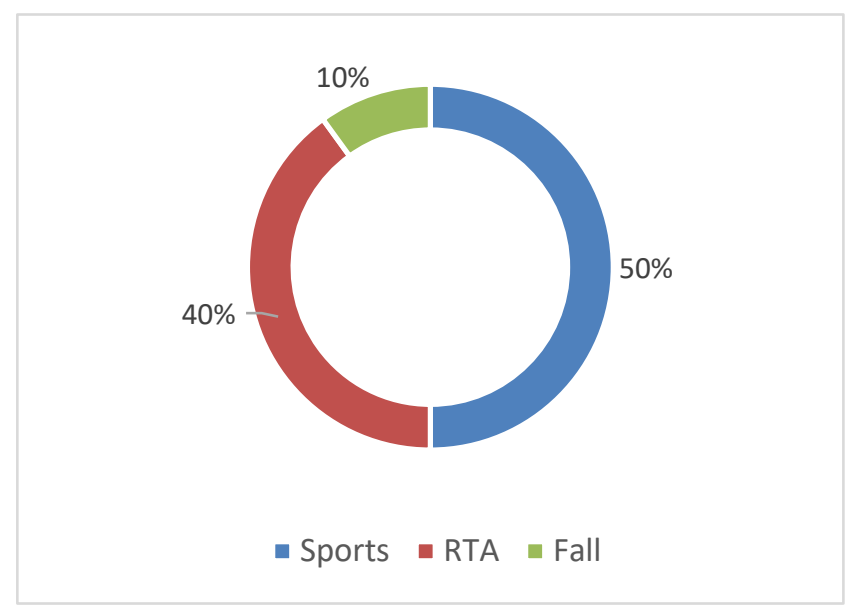

Figure 2: Pie diagram of distribution according to mode of injury.

Outcome evaluation after surgery was assessed by using Lysholm and Gillquist knee scoring scale. The result was found to be good in 16 i.e., 53.3\%, excellent in 10 i.e., $33.3 \%$ and fair in 4 i.e., $13.3 \%$ patients (Table 3 ).

Table 3: Outcome assessment according to Lysholm and Gillquist knee scoring scale.

\begin{tabular}{|llll|}
\hline Variables & Frequency & $\begin{array}{l}\text { Percentage } \\
(\%)\end{array}$ \\
\hline Lysholm & Excellent & 10 & 33.3 \\
\hline $\begin{array}{l}\text { and } \\
\begin{array}{l}\text { Gillquist } \\
\text { knee scoring } \\
\text { scale }\end{array}\end{array}$ & Good & 16 & 53.3 \\
\cline { 2 - 4 } & Fair & 4 & 13.4 \\
\hline
\end{tabular}

Out of 30 patients who underwent surgery, complications were seen in only 7 patients. So, prevalence of complications was reported as $23.3 \%$ in our study. In 4 patients i.e., $13.3 \%$ anterior knee pain was commonly observed complication. Superficial infection, deep infection and extensor leg was seen in 1 patient each i.e., $3.3 \%$ (Table 4).

Table 4: Distribution according to complications.

\begin{tabular}{|clll|}
\hline Variables & Frequency & $\begin{array}{l}\text { Percentage } \\
(\%)\end{array}$ \\
\hline Complications & $\begin{array}{l}\text { Anterior } \\
\text { knee pain }\end{array}$ & 4 & 13.3 \\
\hline $\begin{array}{l}\text { Superficial } \\
\text { infection }\end{array}$ & 1 & 3.3 \\
\cline { 2 - 4 } & $\begin{array}{l}\text { Deep } \\
\text { infection }\end{array}$ & 1 & 3.3 \\
\hline $\begin{array}{l}\text { Extensor } \\
\text { leg }\end{array}$ & 1 & 3.3 \\
\hline
\end{tabular}

\section{DISCUSSION}

At present the most commonly used grafts for ACL reconstructions are bone-patellar tendon-bone autograft and hamstring tendon grafts. The central one third of the bone patellar tendon bone graft was used because of its excellent biomechanical properties. It is the strongest of the immediately available substitute. Precise location of its tissue ends influences joint kinematics. The graft can be placed accurately during the surgery for it to act isometrically both in its location and tension. Bone to bone healing is more secure and rapid when compared to other grafts. It does not sacrifice the knee stabilizers. The bonepatellar tendon-bone graft is time tested and has lesser complications and less significant morbidity.

\section{Age and gender}

We included total 30 patients in our study according to eligibility criteria. In our study, majority of the patients i.e., $13(43.3 \%)$ were from $26-35$ years age group followed by 10 i.e., $33.3 \%$ from $15-25$ years, $5(16.7 \%)$ from $36-45$ years group. Least were from $45-55$ years age group i.e., 2 $(6.7 \%)$ (Table 1).

Male predominance was found in our study. 24 (80\%) patients were males and $6(20 \%)$ patients were females. Male to female ratio was $4: 1$. This was probably because males are more frequently involved in sports and road traffic accidents (Figure 1).

Average age at surgery in the present study group was $28.46 \pm 9.97$ years and that of Jomha et al was 26 years and Bach et al was 25 years. 22,23

Average duration of follow-up of the present study was 12 months with a minimum follow-up period 6 months and maximum follow-up period was 18 months. Average duration of follow-up Bach et al was 26 months. ${ }^{23}$

Elveos et al mentioned 55 women and 45 men in his study. ${ }^{24}$ The mean age at surgery was 25 years (range, 1642 years) for the BPTB group. The mean time from injury to surgery was 40 months (range, 1-180 months) for the BPTB group and 46 months (range, 3-168 months) for the LAD group, and the ACL rupture was detected both clinically and arthroscopically.

Awasthi et al reported that physically active age group (1840 years). ${ }^{25}$ The age of the patients ranged from 18-45 years. The average age was 32.32 years. $92.19 \%$ of patients. Out of the 64 patients, 55 patients $(85.93 \%)$ were male, and nine patients $(14.07 \%)$ were female.

$\mathrm{Lu}$ et al reported that mean age for $35.20 \pm 14.92$ years. ${ }^{26}$ Our findings are comparable with the findings of abovementioned authors. 


\section{Knee laterality}

Out of 30 knee injuries, right sided involvement was seen in 18 patients i.e., $60 \%$ and left sided knee involvement was seen in 12 i.e., $40 \%$ (Table 2).

Awasthi et al reported that right side anterior cruciate ligament deficiency was seen in $36(56.25 \%)$ patients, and left-sided involvement has been observed in 28 (43.75\%) patients. $^{25}$

\section{Outcome and complications}

In our study, outcome evaluation after surgery was assessed by using Lysholm and Gillquist knee scoring scale. The result was found to be good in 16 i.e., $53.3 \%$, excellent in 10 i.e., $33.3 \%$ and fair in 4 i.e., $13.3 \%$ patients. (Table 3).

In our study, out of 30 patients who underwent surgery, complications were seen in only 7 patients. So, prevalence of complications was reported as $23.3 \%$ in our study. In 4 patients i.e., $13.3 \%$ anterior knee pain was commonly observed complication. Superficial infection, deep infection and extensor leg was seen in 1 patient each i.e., $3.3 \%$ (Table 4).

Awasthi et al reported that pain in $9.4 \%$, infection in $7.8 \%$ and stiff knee in $6.25 \%$ patients. ${ }^{26}$

Spindler et al, 104 in their first prospective cohort study of five-year outcomes after ACL reconstruction stated that weight control education and regular exercise leads to an increased functional outcome. ${ }^{27}$ The rehabilitation following surgical reconstruction focuses on three main goals i.e., the restoration of ligament stability, restoration of muscular strength and the restoration and improvement of general state of fitness.

\section{CONCLUSION}

Most commonly affected age group was 15-25 years with male preponderance. Commonest cause of ACL tear was sports injury. In $86.7 \%$ cases, good to excellent result was observed. Prevalence of complications was reported as $23.3 \%$. So, our study of ACL repair using BPTP gives good to excellent results within a span of one year.

Funding: No funding sources Conflict of interest: None declared

Ethical approval: The study was approved by the institutional ethics committee

\section{REFERENCES}

1. Miller RH. Knee injuries: in Campbell's operative. Orthopaedics. 2008;8(2):1186.

2. Butler DL, Noyes FR, Grood ES. Ligamentous restraints to anterior-posterior drawer in human knee.
A biomechanical study. J Bone Joint Surg Am. 1980;62:259-70.

3. Haimes JL, Wroble RR, Grood ES, Noyes FR. Role of medial structures in the intact and anterior cruciate ligament deficient knee. Limits of motion in the human knee. Am J Sports Med. 1994;22:402-9.

4. Markolf KL, Wascher DC, Finerman GAM. Direct invitro, measurement of forces in the cruciate ligament. Part II: The effect of section of the posterolateral structures. J Bone and Joint Surg Am. 1993;75-A;387-394.

5. Arnold JA, Coker TP, Heaton LM. Natural history of anterior cruciate tears. Am J Sports Med. 1979;7:305.

6. Noyes FR, Mooar PA, Matthews DS Butler DL. The symptomatic anterior cruciate-deficient knee. I. The long-term functional disability in athletically active individual. J Bone Joint Surg. 1983;65-A:154.

7. McGinty JB. Arthroscopic surgery in sports injuries. Orthop Clin North Am. 1980;11:787.

8. Cambell WC. Reconstruction of the ligaments of the Knee. Am J Surg. 1939;43:473.

9. Jones KG. Reconstruction of the anterior cruciate ligament using the central one-third of the patellar ligament. J Bone joint Surg. 1970;52-A:1302.

10. Insall JN, Joseph DM, Aglietti P, Campbell RD Jr. Bone-block iliotibial band transfer for anterior cruciate insufficiency. J Bone Joint Surg. 1981;63A:560.

11. Clancy WG, Nelson DA, Reider B. Narechania RG: Anterior cruciate ligament reconstruction using one third of the patellar ligament, augmented by extraarticular tendon transfer. J Bone joint Surg. 1982;64A:352

12. Puddu G. method for reconstruction of anterior cruciate ligament using the semitendinosus tendon. Am J Sports Med. 1980;8:402.

13. Shaieb MD, Kan DM, Chang SK, Marumoto JM, Richardson AB. A prospective randomized comparison of patellar versus semitendinosus and gracillis tendon autografts for anterior cruciate ligament reconstruction. Am J Sports Med. 2002;30:214-20.

14. Barret GR, Noojin FK, Hartzog CW, Nash SR. Reconstruction of the anterior cruciate ligament in females. A comparison of hamstring versus patellar tendon autograft. Arthroscopy. 2002;18:46-54.

15. Ejerhed L, Kartus J, Sernert N, Kohler K, Karlsson J. Patellar tendon or semitendinosus tendon autografts for anterior cruciate ligament reconstruction: A prospective randomized study with a two-year followup. Am J Sports Med. 2003;31:19-25.

16. Jansson KA, Linko E, Sandelin J, Harilainen A. A prospective randomized study of patellar versus hamstring tendon autografts for anterior cruciate ligament reconstruction. Am J Sports Med. 2003;31:12-8.

17. Pinczewski LA, Deehan DJ, Salmon LJ, Russell VJ, Clingeleffer A. A five-year comparison of patellar tendon versus four-strand hamstring tendon autograft 
for arthroscopic reconstruction of the anterior cruciate ligament. Am J Sports Med. 2002;30:523-36.

18. Beynnon BD, Johnson RJ, Fleming BC, Kannus P, Kaplan M, Samani J et al. Anterior cruciate ligament replacement: comparison of bone-patellar tendonbone grafts with two strand hamstring grafts. J Bone Joint Surg (Am). 2002;84:1503-13.

19. Aglietti P, Buzzi R, Zaccherotti G, DeBiase P. Patellar tendon versus doubled semitendinosus and gracillis tendons for anterior cruciate ligament reconstruction. Am J Sports Med. 1994;22:211-8.

20. Marder RA, Raskind JR, Carroll M. Prospective evaluation of arthroscopically assisted anterior cruciate ligament reconstruction. Patellar tendon versus semitendinosus and gracillis tendons. Am J Sports Med. 1991;19:478-84.

21. Lysholm J, Gillquist J. Evaluation of knee ligament surgery results with special emphasis on use of a scoring scale. Am J Sports Med. 1982;10:150-4.

22. Jomha NM, Pinczewski LA, Clingeleffer A, Otto A. Arthroscopic reconstruction of anterior cruciate ligament with patellar-tendon autograft and interference screw fixation. The results at seven years. J Bone Joint Surg (Br). 1999;81:775-9.

23. Bach BR, Tradonsky S, Bojchuk J, Levy ME, BushJoseph CA, Khan NH. Arthroscopically assisted ACL reconstruction using patellar tendon autograft. Fiveto nine-year follow-up evaluation. Am J Sports Med. 1998;26:20-9.
24. Elveos MM, Drogset JO, Engebretsen L, Brønn R, Lundemo, Gifstad T. Anterior Cruciate Ligament Reconstruction Using a Bone-Patellar Tendon-Bone Graft with and Without a Ligament Augmentation Device A 25-Year Follow-up of a Prospective Randomized Controlled Trial. Orthopaedic J Sports Med. 2020;6(11):1-8

25. Awasthi S, Mahapatra S, Aggarwal P, Tripathy SS, Yadav RRS, Verma C. Analysis of fixation modalities in arthroscopic anterior cruciate ligament reconstruction. Int J Orthop Sci. 2017;3(4):102-5.

26. Lu C, Huang X. The comparison of clinical efficacy of arthroscopic anterior cruciate ligament reconstruction via autologous bone-patellar tendonbone, autologous hamstring tendon and allogeneic bone-patellar tendon-bone. Int J Clin Exp Med. 2017;10(8):12277-84.

27. Anders JO, Struwe MS, Sander K, Layher F, Venbrocks RA. Radiological and clinical functional examinations 36 months after anterior cruciate ligament repair by a patellar tendon graft. Orthop Unfall. 2007;145(6):719-25.

Cite this article as: Singh KJK, Prasad VKV, Singh TA, Takalkar AA. Functional outcome of anterior cruciate ligament reconstruction using bone-patellar tendon-bone graft: a descriptive observational study from Telangana. Int J Res Orthop 2021;7:467-71. 